\title{
Absorção, translocação e efeitos metabólicos do glyphosate em plantas de eucalipto
}

\author{
Absorption, translocation and metabolic effects \\ of glyphosate by Eucalyptus plants
}

\author{
Edicarlos Batista de Castro1, Caio Antonio Carbonari², Edivaldo Domingues Velini ${ }^{3}$, \\ Diego Belapart ${ }^{4}$, Giovanna Larissa Gimenes Cotrick Gomes ${ }^{5}$ e Ronei Ben ${ }^{4}$
}

\begin{abstract}
Resumo
Objetivou-se avaliar a absorção e a translocação do glyphosate aplicado em diferentes posições em plantas de eucalipto (clone de Eucalyptus urograndis). Foram realizados dois experimentos em casa de vegetação em delineamento inteiramente casualizado, com quatro repetições. No primeiro experimento, adotou-se esquema fatorial $3 \times 2$, em que o fator A correspondeu ao local de aplicação na planta (aplicação na parte superior, inferior e a testemunha sem aplicação) e o fator B ao local da coleta na planta (parte superior e inferior). O segundo ensaio foi em esquema fatorial $2 \times 2$, em que o fator A correspondeu ao local de aplicação na planta com um galho protegido (galho protegido na parte superior e inferior) e o fator $B$ ao local da coleta na planta (superior e inferior). As mudas foram plantadas em vasos contendo 5 litros de solo. Aos 50 dias após o plantio realizou-se a aplicação do glyphosate ( $360 \mathrm{~g}$ e.a. ha-1) em ambos os experimentos e a coleta aos 4 dias após a aplicação (DAA). O glyphosate, ácido aminometilfofônico (AMPA) e ácido chiquímico foram quantificados por cromatografia líquida e espectrometria de massas (LC-MS/MS). Aos 7, 14 e 21 DAA foi realizada a avaliação de intoxicação e a massa seca das plantas foi mensurada ao final do experimento. Não foram detectados níveis de AMPA nas folhas. A maior porcentagem de absorção observada foi na aplicação sobre a parte superior da planta. Os níveis de ácido chiquímico nas plantas aplicadas foram superiores aos encontrados na testemunha, indicando que houve intoxicação nas plantas. A aplicação de glyphosate na parte superior da planta causou maiores níveis de intoxicação e independentemente do local que recebeu a aplicação houve redução de massa seca das plantas de eucalipto. Portanto, conclui-se que o glyphosate após ser absorvido possui mobilidade em plantas de eucalipto, porém a não deteç̧ão do AMPA demonstra que o glyphosate não foi metabolizado na planta.
\end{abstract}

Palavras-chave: ácido chiquímico, Eucalyptus urograndis, intoxicação.

\begin{abstract}
The aim of this study was to evaluate the absorption and the translocation of glyphosate applied in different positions at eucalyptus plants (Eucalyptus urograndis clone). Two experiments were conducted in a greenhouse on a completely randomized design with four replications. In the first experiment, a $3 \times 2$ factorial arrangement was adopted, where the factor $A$ corresponded to the application spot on the plant (application on top, bottom and control without application) and factor B to the collection spot on the plant (top and lower). The second test was $2 \times 2$ factorial, where factor A corresponded to the application spot on the plant with a protected branch (branch protected on top and bottom) and factor $B$ to the collection spot on the plant (top and bottom). The seedlings were planted in pots containing 5 liters of soil. 50 days after planting, glyphosate (360 g e.a. ha-1) was applied on both experiments and gathering occurred 4 days after application (DAA). Glyphosate, amino-methyl-phophonic acid (AMPA) and shikimic acid were quantified
\end{abstract}

\footnotetext{
1Doutorando em agronomia. UNESP - Universidade Estadual Paulista "Júlio de Mesquita Filho" / FCA - Faculdade de Ciências Agrárias Fazenda Lageado. Rua José Barbosa de Barros, 1780 - 18610-307 - Botucatu, SP, Brasil. E-mail: castroeb@hotmail.com.

2Professor Assistente Doutor. UNESP - Universidade Estadual Paulista "Júlio de Mesquita Filho" / FCA - Faculdade de Ciências Agrárias Fazenda Lageado. Rua José Barbosa de Barros, 1780 - 18610-307 - Botucatu, SP, Brasil. E-mail: carbonari@fca.unesp.br.

3Professor Titular. UNESP - Universidade Estadual Paulista "Júlio de Mesquita Filho" / FCA - Faculdade de Ciências Agrárias Fazenda Lageado. Rua José Barbosa de Barros, 1780 - 18610-307 - Botucatu, SP, Brasil. E-mail: velini@fca.unesp.br.

${ }^{4}$ Mestrando em agronomia. UNESP - Universidade Estadual Paulista “Júlio de Mesquita Filho" / FCA - Faculdade de Ciências Agrárias Fazenda Lageado. Rua José Barbosa de Barros, 1780 - 18610-307 - Botucatu, SP, Brasil. E-mail: diegobelapartt@hotmail.com; roneiben@hotmail.com.

${ }^{5}$ Pós doutoranda. UNESP - Universidade Estadual Paulista "Júlio de Mesquita Filho" / FCA - Faculdade de Ciências Agrárias Fazenda Lageado. Rua José Barbosa de Barros, 1780 - 18610-307 - Botucatu, SP, Brasil. E-mail: giovanna.gomes@fca.unesp.br.
}

Sci. For., Piracicaba, v. 44, n. 111, p. 719-727, set. 2016 DOI: dx.doi.org/10.18671/scifor.v44n111.18 
by liquid chromatography and mass spectrometry (LC-MS / MS). At 7, 14 and 21 DAA. The evaluation of intoxication and, at the end of the experiment, the dry mass of the plants was measured. AMPA levels were not detected in leaves. The highest percentage of absorption was observed in the application on the top of the plant. The shikimic acid levels on the applied plants were higher than those found on the controls. The application of glyphosate to the top of plant caused higher levels of poisoning and regardless which spot received the application, there was a reduction of the dry mass of eucalyptus plants. Therefore, glyphosate, after being absorbed, has mobility in eucalyptus plants, but the absence of the detection of AMPA shows that glyphosate was not metabolized in the plant.

Keywords: shikimic acid, Eucalyptus urograndis, intoxication.

\section{INTRODUÇÃO}

O setor florestal possui grande importância para o País, sendo o eucalipto, a espécie mais utilizada em reflorestamento, por apresentar características de rápido crescimento, adaptação a diferentes condições ambientais e boa competitividade quanto ao seu estabelecimento no campo. Entretanto, a interferência pelas plantas daninhas na cultura do eucalipto causa grandes prejuízos, principalmente o decréscimo quantitativo da sua produção.

Com a necessidade de atingir altos índices de produtividade dentro de um limite econômico aceitável, o método químico é o mais utilizado para o controle de plantas daninhas, porém, poucos são os herbicidas registrados para a cultura do eucalipto, entre os quais o glyphosate é o mais utilizado por controlar um grande número de espécies.

$\mathrm{O}$ glyphosate ( $\mathrm{N}$-fosfonometil glicina) é um dos poucos ingredientes ativos registrados para a cultura e recomendado em pós-emergência das plantas daninhas, sendo não seletivo e de amplo espectro de controle. Este herbicida apresenta movimentação tanto simplástica como apoplástica, inibe a enzima 5-enolpiruvil-chiquimato-3-fosfato-sintase (EPSPS), e com isso, provoca o acúmulo de ácido chiquímico e interfere na biossíntese dos aminoácidos aromáticos (triptofano, fenilalanina e tirosina), proteínas e compostos secundários (FRANZ et al., 1997; VELINI et al., 2009).

Em condições favoráveis o glyphosate penetra nas folhas, em seguida atinge as raízes, rizomas e meristemas apicais, pela translocação via floema e xilema, uma vez que o floema é o principal mecanismo de transporte de herbicidas aplicados em pós emergência das plantas daninhas (SATCHIVI et al., 2000). Sua absorção e translocação são fundamentais para alcançar o sítio de ação e representam um fator essencial na eficácia do herbicida.

Na cultura do eucalipto, os prejuízos causados pela deriva do glyphosate reforçam a necessidade de cuidados na aplicação e eficiência no uso da tecnologia de aplicação em áreas de plantio (TUFFI SANTOS et al., 2007). O uso do glyphosate pode causar injúrias severas ao eucalipto além da queda de crescimento e até a morte da planta (COSTA et al., 2012; TUFFI SANTOS et al., 2005, 2006, 2007). Com a simulação de deriva do glyphosate em eucalipto, evidenciou-se o aparecimento de sintomas relacionados ao contato do produto com as plantas, como necrose e clorose foliar após a aplicação (PEREIRA et al., 2011; TUFFI SANTOS et al., 2005).

Assim, é importante compreender a absorção e a translocação do glyphosate após o contato por deriva, em diferentes partes das plantas de eucalipto, além de conhecer os efeitos deste herbicida sobre a rota do ácido chiquímico nesta espécie. Portanto, o objetivo do presente trabalho foi avaliar a absorção e a translocação do glyphosate quando aplicado em diferentes partes da planta de eucalipto do clone urograndis.

\section{MATERIAL E MÉTODOS}

Foram realizados dois experimentos em casa de vegetação no Núcleo de Pesquisas Avançadas em Matologia (NUPAM), pertencente à Faculdade de Ciências Agronômicas - FCA/UNESP, campus de Botucatu/SP. Nos dois experimentos foram plantadas mudas de eucalipto clone urograndis $144 \mathrm{em}$ vasos contendo 5 litros de solo com as seguintes características: 303, 86 e 611 g. $\mathrm{dm}^{-3}$ de argila, silte e areia, $\mathrm{pH}\left(\mathrm{CaCl}_{2}\right)=5,0, \mathrm{M} . \mathrm{O} .=11 \mathrm{~g} \mathrm{dm}^{-3}, \mathrm{P}($ resina $)=15 \mathrm{mg} \mathrm{dm}^{-3}, \mathrm{Al}^{3+}=0$ mmolc dm${ }^{-3}, \mathrm{H}+\mathrm{Al}=41$ mmolc dm ${ }^{-3}, \mathrm{~K}+=0,2$ mmolc dm$^{-3}, \mathrm{Ca}^{2+}=16$ mmolc dm$^{-3}, \mathrm{Mg}^{2+}=6$ mmolc dm${ }^{-3}, \mathrm{SB}=22 \mathrm{mmolc}$ $\mathrm{dm}^{-3} ;$ CTC $(\mathrm{T})=63$ mmolc $\mathrm{dm}^{-3} ; \mathrm{S}=33 \mathrm{mg} \mathrm{dm}^{-3} \mathrm{e} \mathrm{V} \%=35$. 
Os experimentos foram instalados em delineamento inteiramente casualizado com quatro repetições. Para o primeiro experimento, adotou-se esquema fatorial 3 x 2, em que o fator A correspondeu ao local de aplicação de glyphosate na planta de eucalipto (aplicação na parte inferior e proteção da parte superior; aplicação na parte superior e proteção na parte inferior; e testemunha sem aplicação) e o fator B correspondeu ao local da coleta na planta (superior e inferior). Foram utilizadas quatro plantas de eucalipto para quantificação dos compostos e mais quatro plantas para as avaliações visuais de intoxicação e massa seca. No segundo experimento, adotou-se esquema fatorial 2 x 2 e o fator A correspondeu a aplicação na planta com a proteção de um galho inferior e aplicação na planta com proteção de um galho superior; e, o fator B, ao local da coleta na planta, sendo: planta e galho protegido inferior e planta e galho protegido superior.

Aos 50 dias após o plantio das mudas de eucalipto, foi realizada a aplicação dos tratamentos para os dois experimentos. Para a pulverização do herbicida glyphosate foi utilizado um pulverizador estacionário, equipado com quatro pontas XR11002VS, espaçadas em 0,5 m entre si, e dispostas a $0,5 \mathrm{~m}$ de altura em relação às plantas de eucalipto. A pressão de trabalho utilizada foi de $2,0 \mathrm{kgf}$ $\mathrm{cm}^{-2}$, com velocidade de $3,6 \mathrm{~km} \mathrm{~h}^{-1}$ e consumo de calda de $200 \mathrm{~L} \mathrm{ha}^{-1}$. O produto comercial utilizado para o preparo da calda de pulverização foi o Roundup Original ${ }^{\circledR}$ (360 g e.a. $\mathrm{L}^{-1}$ ), na dose de $360 \mathrm{~g}$ e.a. ha ${ }^{-1}$. A aplicação iniciou-se às 10:00 horas da manhã e foi finalizada às 13:00 horas com temperatura média de $27,3^{\circ} \mathrm{C}$ e umidade relativa média de $57,5 \%$.

Aos 4 dias após a aplicação (DAA) do gliphosate no primeiro experimento, foi realizada a coleta de todas as folhas de quatro plantas por tratamento. Em seguida, as folhas foram acondicionadas em sacos plásticos e lavadas por três vezes com $100 \mathrm{~mL}$ de água destilada para total remoção do glyphosate que ficou depositado sobre as folhas de eucalipto. A água proveniente das três lavagens foi misturada e resultou em apenas uma amostra composta para posterior quantificação do glyphosate.

Após a lavagem, as folhas foram acondicionadas em sacos de papel para secagem em estufa de circulação forçada de ar a $40^{\circ} \mathrm{C}$, por cinco dias. As amostras secas foram maceradas em nitrogênio líquido e acondicionadas em sacos plásticos em freezer a $-80^{\circ} \mathrm{C}$ para posterior extração e quantificação dos compostos.

Foram utilizadas mais 4 plantas (repetições) por tratamento para as avaliações visuais de intoxicação na planta toda aos 7, 14 e 21 DAA; e, por partes da planta (superior e inferior) aos 7 e 21 DAA segundo escala percentual de notas, onde: " 0 "corresponde a nenhuma injúria e " 100 " significa a morte das plantas, conforme SBCPD (1995). No final das avaliações visuais, as folhas e o caule das plantas foram coletados e acondicionados em sacos de papel, e secos em estufa a $60^{\circ} \mathrm{C}$, por um período de 72 horas. Posteriormente, o material seco foi pesado para determinação da massa seca em cada um dos tratamentos.

No segundo experimento foi realizada a coleta de todas as folhas de quatro plantas por tratamento também aos 4 DAA, e não foram realizadas avaliações visuais de intoxicação nas plantas. Após a coleta, as folhas foram lavadas assim como no primeiro experimento, porém apenas para total remoção dos resíduos sobre as folhas. Após a lavagem, as folhas foram acondicionadas em sacos de papel para secagem em estufa de circulação forçada de ar, a $40^{\circ} \mathrm{C}$, por cinco dias.

A extração e a quantificação dos compostos analisados (glyphosate, AMPA e ácido chiquímico) foi realizada de acordo com o método proposto por Gomes et al. (2015). Para a solução da lavagem das folhas, fez-se apenas a filtragem (filtro Millex HV 0,45 $\mu \mathrm{m}$ com membrana durapore $13 \mathrm{~mm}$ ) e acondicionamento em recipiente de vidro âmbar. A quantificação foi realizada por um cromatógrafo líquido de alta eficiência acoplado a um espectrômetro de massas (LC-MS/MS).

O tempo de retenção dos compostos na coluna cromatográfica foi: glyphosate 2,89 minutos; AMPA 2,89 minutos e ácido chiquímico 2,95 minutos. A partir da quantificação dos teores de glyphosate nas plantas e na água utilizada para remover o produto depositado sobre as plantas, calculou-se a porcentagem de absorção de glyphosate de acordo com seguinte equação:

$$
\% G A F=(T A F * 100) / T D S F
$$

Onde: $\% G A F=$ porcentagem de glyphosate absorvido pelas folhas; $T A F=$ total absorvido pelas folhas; e TDSF = total depositado na superfície da folha. Para o cálculo não foi considerado o glyphosate presente no caule, translocado para as raízes e o exsudato. 
Os dados das concentrações dos compostos avaliados $\left(\mu \mathrm{g} \mathrm{g}^{-1}\right)$ nos diferentes períodos, análise visual e massa seca das plantas, foram submetidos à análise de variância pelo teste $\mathrm{F}$, e as médias comparadas pelo teste de Tukey a 5\% de probabilidade. Para a porcentagem de absorção de glyphosate nas plantas de eucalipto foi realizado o intervalo de confiança pelo teste $t$ a $10 \%$ de probabilidade. Para determinar o intervalo de confiança, foi utilizada a equação:

$$
I C=(t x \text { desvpad }) / \text { raiz } n r,
$$

Onde: $I C=$ intervalo de confiança; $t=$ valor de $t$ tabelado, ao nível de $10 \%$ de probabilidade; desvpad = desvio padrão; e raiz $n r$ = raiz quadrada do número de repetições.

\section{RESULTADOS E DISCUSSÃO}

A aplicação de glyphosate na parte superior das plantas de eucalipto proporcionou maior absorção do herbicida e maiores sintomas de fitointoxicação quando em comparação ao observado na parte inferior das plantas (Figura 1).

A cutícula foliar é a principal via de penetração do glyphosate e sua espessura influencia na absorção do herbicida, por isso, os resultados encontrados podem ser explicados pelo fato da seção superior das plantas apresentarem maior quantidade de folhas em desenvolvimento em relação à parte inferior. De acordo com Souza (2008), as folhas mais desenvolvidas em plantas de eucalipto apresentaram maior espessura das cutículas abaxial e adaxial, maior espessura do parênquima paliçádico adaxial, maior porcentagem de parênquima paliçádico, maior número e área de cavidades oleíferas, menor espessura da epiderme abaxial e menor espessura e porcentagem de parênquima lacunoso.

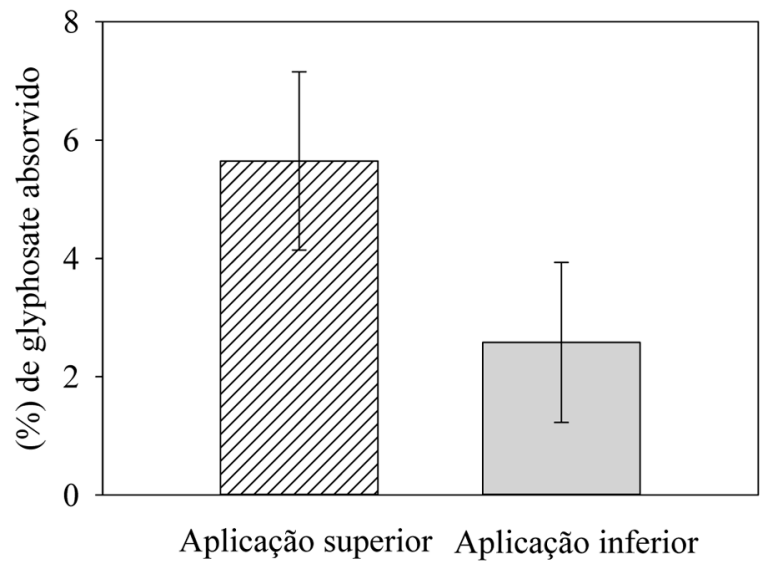

Figura 1. Níveis de absorção de glyphosate em diferentes locais de aplicação em plantas de eucalipto. Botucatu/SP, 2015. Figure 1. Glyphosate absorption levels in different application positions in eucalyptus plants. Botucatu/SP, 2015.

Quando a aplicação do primeiro experimento foi realizada na parte inferior das plantas de eucalipto, verificaram-se sintomas de intoxicação, caracterizados por manchas cloróticas em toda a planta. Houve pouca progressão dos sintomas nas avaliações dos 7 aos 21 DAA. Entretanto, maiores danos foram observados nas plantas de eucalipto com a aplicação de glyphosate na parte superior (Tabela 1).

As plantas que receberam aplicação de glyphosate apresentaram redução significativa da massa seca quando comparados com a testemunha, evidenciando a intoxicação nas plantas (Tabela 1). Diversos trabalhos demonstraram que o contato do glyphosate por meio de deriva pode causar decréscimo quantitativo no eucalipto (COSTA et al., 2012; PEREIRA et al., 2011; TUFFI SANTOS et al., 2005; 2006; 2007). Segundo Tuffi Santos et al. (2007), as plantas de eucalipto que apresentaram sintomas visuais de intoxicação acima de $21 \%$ tiveram crescimento inferior àquelas sem intoxicação.

O ácido aminometilfosfônico (AMPA) não foi detectado nas amostras do primeiro experimento. Desta forma, evidenciou-se que o glyphosate não foi metabolizado no interior da planta. Os maiores níveis de glyphosate foram proporcionados pela aplicação diretamente no local da coleta, entretanto, quando ocorreu a aplicação na parte inferior da planta, verificou-se a translocação para o local que não recebeu o produto (Figura 2). O glyphosate não foi detectado nas plantas que não receberam a aplicação. 
Tabela 1. Avaliação visual de intoxicação aos 7,14 e 21 DAA e massa seca do eucalipto submetido à aplicação de glyphosate em diferentes posições na planta.

Table 1. Visual assessment of intoxication at 7,14 and 21 DAA and dry mass of eucalyptus submitted to the application of glyphosate in different positions in the plant.

\begin{tabular}{lcccc}
\hline \multirow{2}{*}{ Tratamentos } & \multicolumn{3}{c}{ Intoxicação (\%) } & \multirow{2}{*}{ Massa Total } \\
\cline { 2 - 4 } & 7 DAA & 14 DAA & 21 DAA & $30,88 \mathrm{~A}$ \\
Testemunha & $0 \mathrm{~B}$ & $0 \mathrm{C}$ & $0 \mathrm{C}$ & $22,04 \mathrm{~B}$ \\
Parte Superior & $30 \mathrm{~A}$ & $45 \mathrm{~A}$ & $50 \mathrm{~A}$ & $22,76 \mathrm{~B}$ \\
Parte Inferior & $27,5 \mathrm{~A}$ & $33 \mathrm{~B}$ & $33,75 \mathrm{~B}$ & $8,439^{*}$ \\
F & $399^{*}$ & $209,07^{*}$ & $87,14^{*}$ & 13,41 \\
C.V. (\%) & 8,7 & 12,4 & 19,57 & \\
\hline
\end{tabular}

* Significativo a $5 \%$ de probabilidade pelo teste $\mathrm{F}$. Médias seguidas por mesma letra maiúscula na coluna não diferem entre si.

De acordo com Duke e Powles (2008), após a aplicação foliar, o glyphosate é rapidamente translocado para tecidos jovens de crescimento como as raízes e parte aérea, onde pode acumular-se em diferentes concentrações. Segundo Machado et al. (2009), o movimento do glyphosate na planta está associado ao fluxo de carboidratos de órgãos tidos como fontes, para os drenos metabólicos, e sua velocidade de translocação para as raízes está associada ao transporte de açúcares no floema.

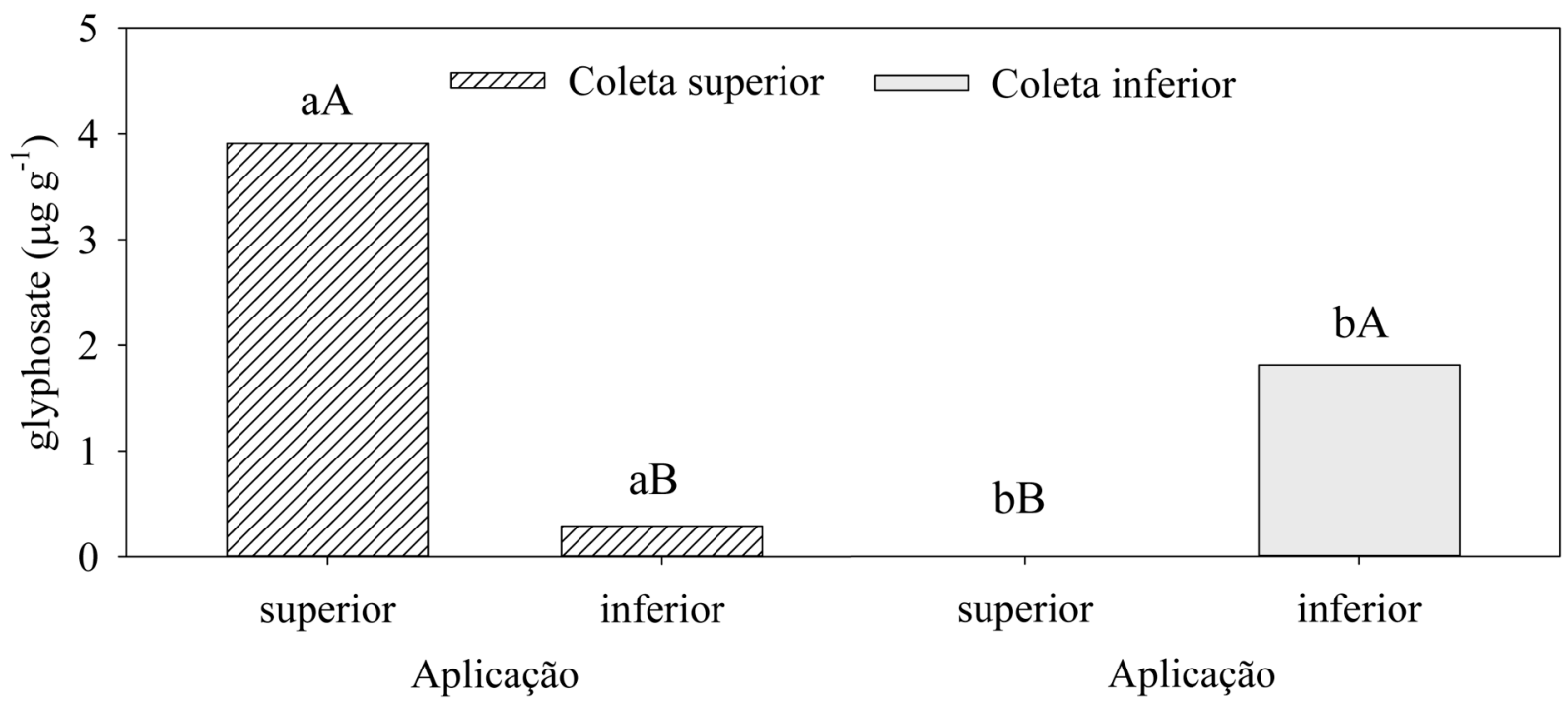

Médias seguidas pela mesma letra maiúscula nas duas modalidades de coleta, e minúscula em cada modalidade de aplicação, não diferem entre si pelo teste Tukey a $5 \%$ de probabilidade. C.V: $26,84 \%$.

Means followed by the same capital letter in the two types of sample leaves, and lower letter in each application mode, do not differ by Tukey test at $5 \%$ probability. C.V: $26,84 \%$.

Figura 2. Níveis de glyphosate em plantas de eucalipto submetidos à aplicação de glyphosate. Botucatu/SP, 2015.

Figura 2. Glyphosate levels in eucalyptus plants submitted to the application of glyphosate. Botucatu/SP, 2015.

Assim como observado no primeiro experimento, também não foram detectados AMPA nas plantas que receberam a aplicação de glyphosate no segundo experimento. O glyphosate apresentou comportamento semelhante entre os experimentos e o herbicida não foi encontrado nas plantas que não receberam aplicação. Quando o glyphosate foi aplicado em toda planta, com o galho protegido na parte superior, identificou-se concentração similar em ambos os locais, ficando evidente a translocação para o local que não recebeu o produto (Figura 3).

Para a aplicação na planta toda, com um galho inferior protegido, verificaram-se baixas concentrações do glyphosate no local em que não recebeu a aplicação do glyphosate (Figura 3). Dessa forma, pode-se afirmar que o herbicida tem menor tendência a se translocar para as folhas da parte de baixo da planta de eucalipto, fato também observado no primeiro experimento. Isto ocorre em função do glyphosate ser muito móvel no floema, acumulando-se nos órgãos dreno. Em trabalho com absorção e translocação de glyphosate em dois clones de eucalipto, Machado et al. (2009) observaram que duas horas após a aplicação, 51,7 e 57,4\% de todo o herbicida absorvido pelas plantas foram detectados no sistema radicular de dois clones de Eucalyptus grandis (2277 e 531), respectivamente. 


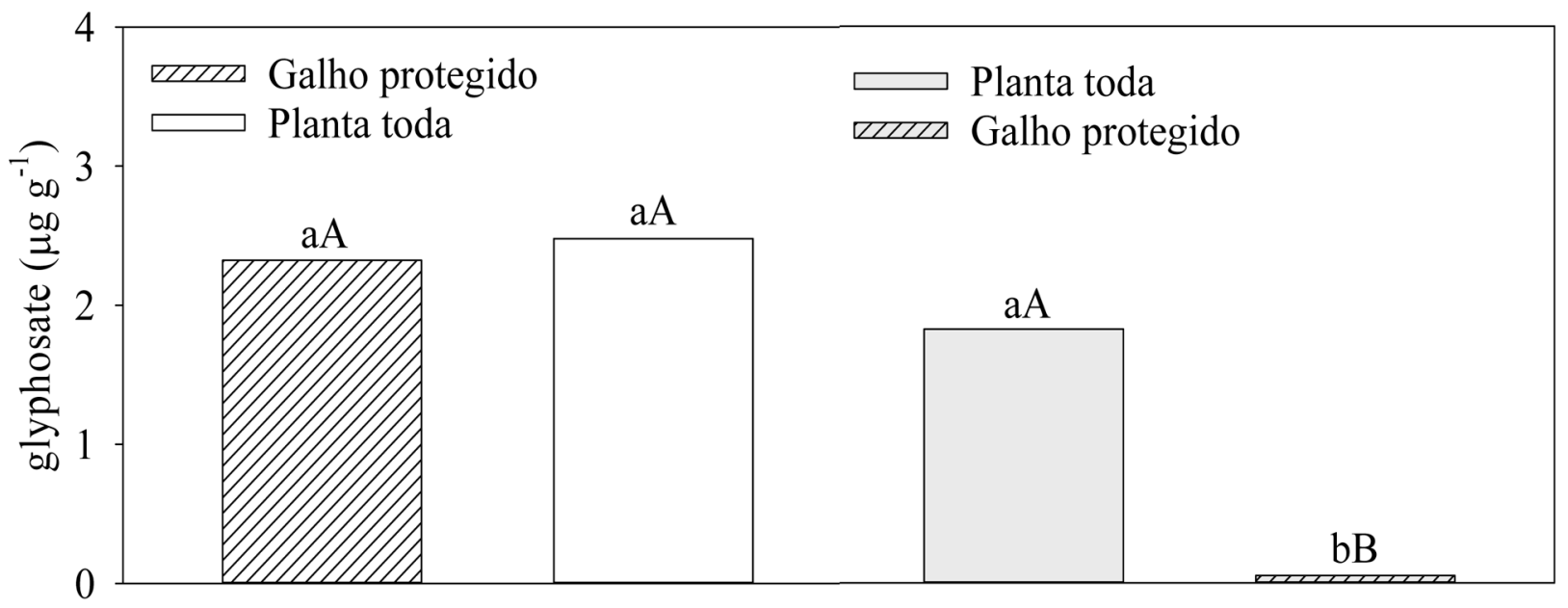

Aplicação com galho superior protegido Aplicação com galho inferior protegido

Médias seguidas por mesma letra maiúscula, em cada coleta, e minúscula, em cada aplicação, não diferem entre si pelo teste Tukey a 5\% de probabilidade de erro. C.V. $29,08 \%$.

Means followed by the same capital letter in each collection, and lower letter in each application, do not differ by Tukey test at $5 \%$ error probability. C.V. $29,08 \%$.

Figura 3. Níveis de glyphosate em plantas de eucalipto com galhos protegidos na seção superior e inferior. Botucatu/SP, 2015.

Figure 3. Glyphosate levels in eucalyptus plants with protected branches in the upper and lower section. Botucatu/SP, 2015.

A aplicação de glyphosate no primeiro experimento em diferentes partes da planta resultou em maiores concentrações de ácido chiquímico nos locais onde ocorreu contato direto entre o herbicida e a folha. Verificou-se que, quanto maior a concentração de glyphosate encontrada na planta, mais ácido chiquímico foi acumulado (Figura 4).

Segundo Bonini et al. (2009), o acúmulo do ácido chiquímico representa um resultado direto da inibição da EPSPS. Diversos autores relataram o aumento dos níveis de ácido chiquímico em plantas de milho não resistentes ao glyphosate (REDDY et al., 2010), folhas de ervilha (ORCARAY, 2010), folhas de Brachiaria decumbens e cana-de-açúcar (MATALLO et al., 2009) e plântulas de Brassica napus (PETERSEN et al., 2007).

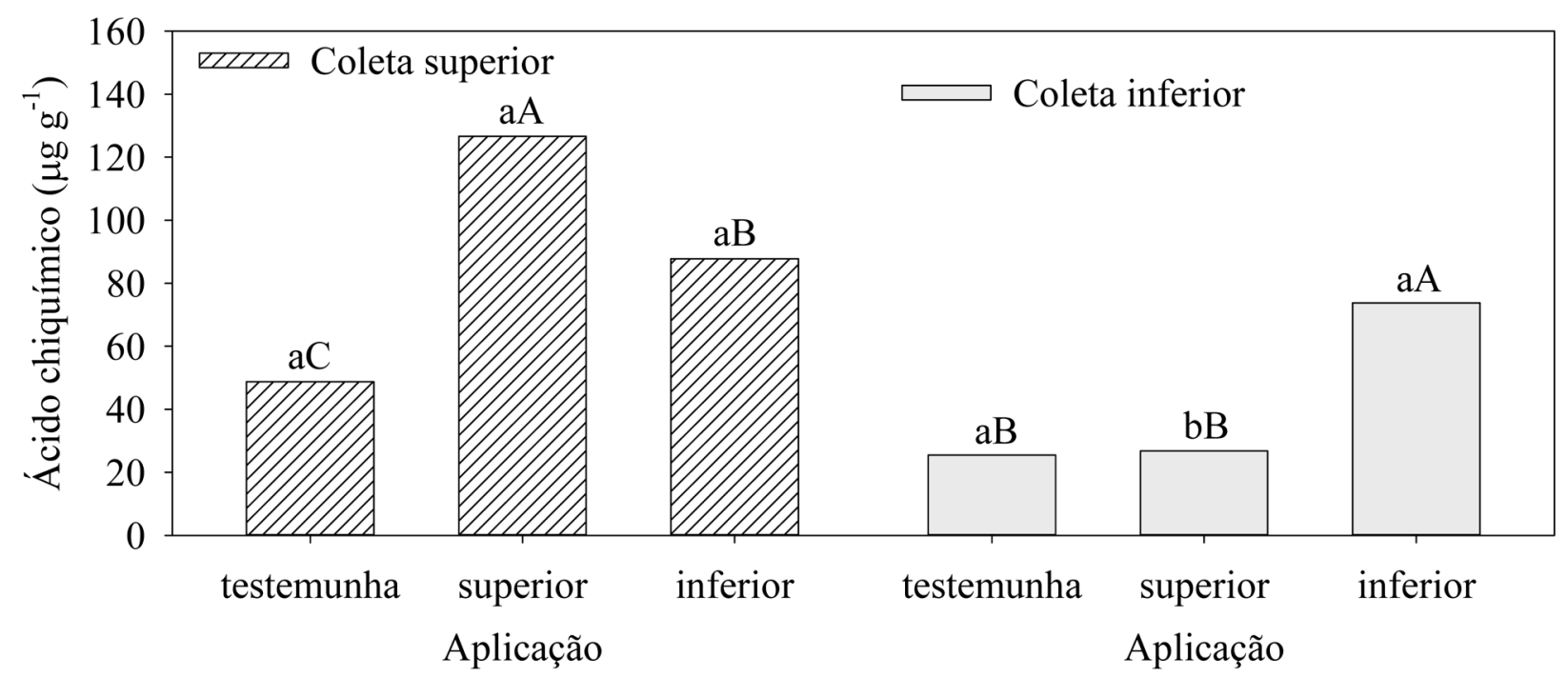

Médias seguidas por mesma letra maiúscula dentro de cada modalidade de coleta, e minúscula em cada modalidade de aplicação, não diferem entre si pelo teste Tukey a $5 \%$ de probabilidade. C.V $32,82 \%$.

Means followed by the same capital letter in each mode of collection, and lower in each application mode, do not differ by Tukey test at $5 \%$ probability. C.V. $32,82 \%$.

Figura 4. Níveis de ácido chiquímico em plantas de eucalipto submetidos à aplicação de glyphosate. Botucatu/SP, 2015.

Figure 4. Shikimic acid levels in eucalyptus plants submitted to the application of 'glyphosate. Botucatu/SP, 2015. 
O aumento do ácido chiquímico caracterizado pelas diferentes concentrações de glyphosate encontrados nas folhas observado no primeiro experimento, também foi evidenciado no segundo experimento. A maior concentração de ácido chiquímico foi verificada na aplicação sobre toda a planta com o galho superior protegido (Figura 5). O ácido chiquímico pode ser um importante parâmetro para identificar intoxicação em plantas. Pois, o bloqueio da rota do ácido chiquímico acumula elevados níveis de ácido chiquímico (BUEHRING et al., 2007; HENRY et al., 2007; PLINE et al., 2002).

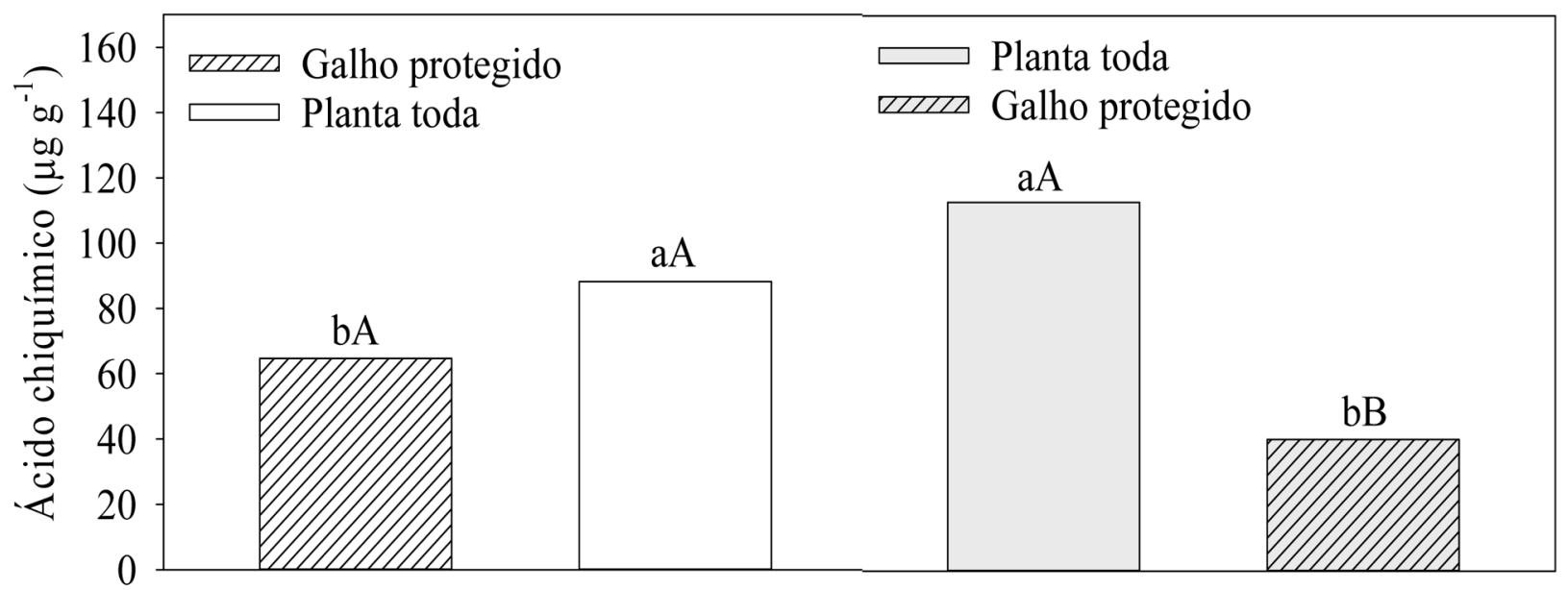

Aplicação com galho superior protegido Aplicação com galho inferior protegido

Médias seguidas por mesma letra maiúscula, em cada coleta, e minúscula, em cada aplicação, não diferem entre si pelo teste Tukey a 5\% de probabilidade. C.V. 26,19\%.

Means followed by the same capital letter in each of sample leaves, and lower letter in each application, do not differ by Tukey test at $5 \%$ probability. C.V. $26,19 \%$.

Figura 5. Ácido chiquímico em plantas de eucalipto submetidos à aplicação de glyphosate em toda planta com gaIhos protegidos na seção superior e inferior. Botucatu/SP, 2015.

Figure 5. Shikimic acid in eucalyptus plants submitted to the application of glyphosate in every plant with branches protected in the upper and lower section. Botucatu/SP, 2015.

A intoxicação do eucalipto no primeiro experimento aos 7 DAA, demonstrou que o herbicida causou maiores injúrias na parte superior da planta de eucalipto quando esta recebeu aplicação no local, verificando-se necrose e morte de algumas folhas, entretanto, na parte inferior não foram observados sintomas. Quando o herbicida foi aplicado na parte inferior, algumas folhas apresentaram clorose e necrose no local do contato com o herbicida. Também, observou-se início de sintomas de intoxicação na parte superior que não recebeu o produto, por isso é possível dizer que houve a translocação do glyphosate para a seção superior da planta (Tabela 2).

Tabela 2. Avaliação visual de intoxicação aos 7 e 21 DAA e massa seca de plantas de eucalipto submetidas à aplicação de glyphosate em diferentes posições na planta.

Table 2. Visual assessment of intoxication at 7 and 21 DAA and dry mass eucalyptus plants submitted to the application of glyphosate in different positions in the plant.

\begin{tabular}{|c|c|c|c|c|c|c|}
\hline \multirow{3}{*}{ Local da aplicação } & \multicolumn{4}{|c|}{ Intoxicação (\%) } & \multirow{2}{*}{\multicolumn{2}{|c|}{ Massa seca $(\mathrm{g})$}} \\
\hline & \multicolumn{2}{|c|}{7 DAA } & \multicolumn{2}{|c|}{21 DAA } & & \\
\hline & Superior & Inferior & Superior & Inferior & Superior & Inferior \\
\hline Testemunha & $0 \mathrm{aC}$ & $0 \mathrm{aB}$ & $0 \mathrm{aC}$ & $0 \mathrm{aC}$ & $10,1 \mathrm{bA}$ & 20,9 aA \\
\hline Parte Superior & 76,3 aA & $0 \mathrm{bB}$ & 97,3 aA & $8,5 \mathrm{bB}$ & $4,7 \mathrm{bB}$ & $18,1 \mathrm{aA}$ \\
\hline Parte Inferior & 9,3 bB & $40 \mathrm{aA}$ & 20,8 bB & 56,3 aA & 10,9 aA & $11,1 \mathrm{aB}$ \\
\hline F Coleta & \multicolumn{2}{|c|}{$197,952^{*}$} & \multicolumn{2}{|c|}{$208,433^{*}$} & \multicolumn{2}{|c|}{$50,397^{\star}$} \\
\hline F Aplicação & \multicolumn{2}{|c|}{$428,779^{*}$} & \multicolumn{2}{|c|}{$659,306^{*}$} & \multicolumn{2}{|c|}{$6,202^{*}$} \\
\hline F Col x Apl & \multicolumn{2}{|c|}{$870,532^{*}$} & \multicolumn{2}{|c|}{$903,211^{*}$} & \multicolumn{2}{|c|}{$12,698^{*}$} \\
\hline C.V. $(\%)$ & \multicolumn{2}{|c|}{12,62} & \multicolumn{2}{|c|}{9,89} & \multicolumn{2}{|c|}{22,12} \\
\hline
\end{tabular}

* Significativo a $5 \%$ de probabilidade pelo teste F. Médias seguidas por mesma letra maiúscula na coluna, e minúscula na linha, não diferem entre si.

$\mathrm{Na}$ análise visual realizada aos 21 DAA, observou-se maior movimento do glyphosate quando aplicado na parte inferior das plantas de eucalipto, pois além de causar intoxicação no local que 
recebeu a aplicação, também provocou sintomas de intoxicação, na parte superior que não recebeu aplicação. Quando ocorreu a aplicação na parte superior observaram-se altos níveis de intoxicação no local da aplicação. Segundo Carvalho et al. (2015), outras consequências pela exposição ao glyphosate são clorose e redução do crescimento de plantas, principalmente em tecidos metabolicamente ativos, tais como folhas imaturas, brotos, botões florais e raiz. Quando se avaliou a massa seca, os resultados obtidos apresentaram semelhança com a avaliação de intoxicação. As injúrias causadas pelo glyphosate proporcionaram redução na massa das plantas de eucalipto (Tabela 2).

\section{CONCLUSÕES}

O glyphosate possui maior absorção quando aplicado em folhas jovens de plantas de eucalipto e possui translocação intensa da parte inferior para a parte superior, mas não ocorre em grande intensidade da parte superior para a inferior. A não detecção do AMPA demonstra que o glyphosate não foi metabolizado na planta. Em função do local de maior absorção de glyphosate, os maiores danos foram identificados na parte superior das plantas do eucalipto. O glyphosate causou maior redução da massa seca na parte atingida pelo herbicida e na parte superior mesmo quando a aplicação foi feita na parte inferior da planta de eucalipto.

\section{REFERENCIAS BIBLIOGRÁFICAS}

BONINI, E. A.; FERRARESE, M. L. L.; MARCHIOSI, R.; ZONETTI, P. C.; FERRARESE FILHO, O. A simple chromatographic assay to discriminate between glyphosate-resistant and susceptible soybean (Glycine max) cultivars. European Journal of Agronomy, Montrouge, v. 31, n. 3, p. 173-176, 2009.

BUEHRING, N. W.; MASSEY, J. H.; REYNOLDS, D. B. Shikimic Acid Accumulation in Field-Grown Corn (Zea mays) Following Simulated Glyphosate Drift. Journal of Agricultural and Food Chemistry, Washington, v. 55, n. 3, p. 819-824, 2007.

CARVALHO, B. C., ALVES, P. L. C. A.; COSTA, F. R. Differential response of clones of eucalyptus to glyphosate. Revista Árvore, Viçosa, v. 39, n. 1, p. 177-187, 2015.

COSTA, A. C. P. R.; COSTA, N. V.; PEREIRA, M. R. R.; MARTINS, D. Efeito da deriva simulada de glyphosate em diferentes partes da planta de Eucalyptus grandis. Semina, Londrina, v. 33, n. 5, p. 1663-1672, 2012.

DUKE, S. O.; POWLES, S. B. Glyphosate: a once-in-a-century herbicide. Pest Management Science, New York, v. 64 n. 4 , p. $319-325,2008$.

FRANZ, J. E.; MAO, M. K.; SIKORSKI, J. A. Glyphosate: A Unique Global Herbicide. Washington: American Chemical Society, 1997. 678 p.

GOMES, G. L. G. C.; CARBONARI, C. A.; VELINI, E. D.; TRINDADE, M. L. B.; SILVA, J. R. M. Extraction and simultaneous determination of glyphosate, ampa and compounds of the shikimic acid pathway in plants. Planta Daninha, Viçosa, v. 33, n. 2, p. 295-304, 2015.

HENRY, W. B.; SHANER, D. L.; WEST, M. S. Shikimate accumulation in sunflower, wheat, and proso millet after glyphosate application. Weed Science, Champaign, v. 55, n. 1, p. 1-5, 2007.

MACHADO, A. F. L.; FERREIRA, L. R.; SANTOS, L. D. T.; SANTOS, J. B.; FERREIRA, F.A.; VIANA, R.G. Absorção, translocação e exsudação radicular de glyphosate em clones de eucalipto. Planta Daninha, Viçosa, v. 27, n. 3, p. 549-554, 2009.

MATALLO, M. B.; ALMEIDA, S. D. B.; CERDEIRA, A. L.; FRANCO, D. A.; BLANCO, F. M. G.; MENEZES, P. T. C.; LUCHINI, L. C.; MOURA, M. A. M.; DUKE, S. O. Microwave-assisted solvent extraction and analysis of shikimic acid from plant tissues. Planta Daninha, Viçosa, v. 27, n. Especial, p. 987-994, 2009. 
ORCARAY, L.; IGAL, M.; MARINO, D.; ZABALZA, A.; ROYUELA. M. The possible role of quinate in the mode of action of glyphosate and acetolactate synthase inhibitors. Pest Management Science, New York, v. 66, n. 3, p. 262-269, 2010.

PEREIRA, M. R. R.; RODRIGUES, A. C. R.; CAMPOS, C. F.; FILHO, A. L. M.; MARTINS, D. Absorção de subdoses glyphosate aplicadas em diferentes locais de plantas de eucalipto. Revista Árvore, Viçosa, v. 35, n. 3, p. 589$594,2011$.

PETERSEN, I. L.; HANSEN, H. C. B.; RAVN, H. W.; SØRENSEN, J. C.; SØRENSEN, H. Metabolic effects in rapeseed (Brassica napus L.) seedlings after root exposure to glyphosate. Pesticide Biochemistry and Physiology, San Diego, v. 89, n. 3, p. 220-229, 2007.

PLINE, W. A.; WILCUT, J. W.; DUKE, S. O.; EDMISTEN, K. L.; WELLS, R. Tolerance and accumulation of shikimic acid in response to glyphosate applications in glyphosate-resistant and non glyphosate-resistant cotton (Gossypium hirsutum L.). Journal of Agricultural and Food Chemistry, Washington, v. 50, n. 3, p. 506$512,2002$.

REDDY, K. N.; BELLALOUI, N.; ZABLOTOWICZ, R. M. Glyphosate effect on shikimate, nitrate reductase activity, yield, and seed composition in corn. Journal of Agricultural and Food Chemistry, Washington, v. 58, n. 6, p. 3646-3650, 2010.

SATCHIVI, N. M.; WAX, L. M.; STOLLER, E. W.; BRISKIN, D. P. Absorption and translocation of glyphosate isopropylamine and trimethylsulfonium salts in Abutilon theophrasti and Setaria faberi. Weed Science, Champaign, v. 48, n. 6, p. $675-679,2000$.

SBCPD - SOCIEDADE BRASILEIRA DA CIÊNCIA DAS PLANTAS DANINHAS. Procedimentos para instalação, avaliação e análise de experimentos com herbicidas. Londrina, 1995. 42 p.

SOUZA, R. R. S. Caracterização anatômica quantitativa e composição de óleos essenciais em três estágios foliares de clones de eucalipto e sua relação com a ferrugem. 2008. 114 p. Dissertação (Mestrado em Agronomia/Proteção de Plantas) - Universidade Estadual Paulista "Júlio de Mesquita Filho", Botucatu, 2008.

TUFFI SANTOS, L. D.; FERREIRA, F. A.; FERREIRA, L. R.; DUARTE, W. M.; TIBURCIO, R. A. S.; SANTOS, M. V. Intoxicação de espécies de eucalipto submetidas à deriva do glyphosate. Planta Daninha, Viçosa, v. 24, n. 2, p. 359-364, 2006.

TUFFI SANTOS, L. D.; FERREIRA, F. A.; MEIRA, R. M. S. A.; BARROS, N. F.; FERREIRA, L. R.; MACHADO, A. F. L. Crescimento e morfoanatomia foliar de eucalipto sob efeito de deriva do glyphosate. Planta Daninha, Viçosa, v. 23, n. 1, p. 133-142, 2005.

TUFFI SANTOS, L. D.; MEIRA, R. M. S. A.; FERREIRA, F. A.; SANT'ANNA-SANTOS, B. F.; FERREIRA, L. R. Morphological responses of different eucalypt clones submitted to glyphosate drift. Environmental and Experimental Botany, Brighton, v. 59, n. 1, p. 11-20, 2007.

VELINI, E. D.; MESCHEDE, D. K.; CARBONARI, C. A.; TRINDADE, M. L. B. Modo de ação do glyphosate. In: Glyphosate. Botucatu: FEPAF, 2009. 493 p.

Recebido em 28/09/2015

Aceito para publicação em 16/02/2016

Sci. For., Piracicaba, v. 44, n. 111, p. 719-727, set. 2016

DOI: dx.doi.org/10.18671/scifor.v44n111.18 
